\title{
A IMPORTÂNCIA DA CULTURA LOCAL QUILOMBOLA NA PRÁTICA PEDAGÓGICA COMO CONTRIBUIÇÃO A VALORIZAÇÃO IDENTITÁRIA DOS DISCENTES NA COMUNIDADE VILA DE JUABA, NO MUNCIPIO DE CAMETÁ-PA NO ANO DE 2019.
}

\author{
Autora: Suely Valente dos Santos ${ }^{1}$ \\ CPF 613.749.112-91
}

\section{RESUMO}

Este trabalho buscou abordar a importância da cultura local quilombola no que se refere a prática pedagógica e sua contribuição para a valorização identitária do discente na comunidade de vila de Juaba, no município de Cametá-PA no ano de 2019. Considerou-se que a cultura local está presente em todo espaço escolar devendo ser trabalhada na prática do professor, portanto, muito se tem a fazer para que de fato esteja presente em sala de aula, nesse sentido a relação entre educação e cultura torna-se necessariamente importante para que haja saberes, possibilitando resultados significativos tanto para educandos quanto educadores, pois as unidades educacionais, comunidades, são formadas por sujeitos culturais, que cria e recria elementos, reproduz cultura trazida por sujeitos. Dialogar sobre o saber de comunidades remanescentes de quilombo, em especial na comunidade de vila de Juaba na trajetória de vida a partir de vivências, significa entender que o chamado saberes tradicionais foram criados nas estreitas relações do homem com a natureza. No entanto, a educação se torna uma ferramenta indispensável e eficaz na vida do cidadão, ao promover a inclusão social e valorizar as diferenças e diversidades, constituindo-se como condição essencial para a superação do preconceito e a solidificação de uma sociedade mais justa e humanizada e, a escola é um espaço importante na erradicação do preconceito e pode contribuir no reconhecimento da identidade.

Palavras-chave: Educação. Cultura Local. Prática docente. Inclusão social

\section{INTRODUÇÃO}

A proposta para o desenvolvimento deste trabalho é fazer uma abordagem sobre a prática pedagógica e sua contribuição para a valorização identitária do discente na comunidade de vila de Juaba, no município de Cametá-PA no ano de 2019, prática esta que viabilizará uma melhor aproximação do currículo escolar com a vivência do educando. Para tanto é necessário também abordar neste trabalho a presença africana na comunidade de vilade Juaba. Que mantém na sua tradição cultural crenças, devoções, costumes, herdados de povos quilombolas, que são repassados de forma oral pelos mais idosos.

Também é necessário compreender a relação de práticas pedagógicas com a realidade do aluno, de modo que este trabalho seja um contributo para compreender e desenvolver os conceitos pertinentes a uma consciência crítica, voltado para as abordagens teóricas,

\footnotetext{
1 Graduada em História pela Universidade Estadual do Maranhão (UEMA). Graduada em Pedagogia pela Faculdade Vasconcellos \& Souza. Pós-Graduada em História da Amazônia e Cultura Afro-indígena pela Faculdade de Tapajós (FAT), pós-graduada-Graduada em Ensino de História pela Faculdade de Patrocínio (FAP), pós graduada em Língua Brasileira de Sinais - LIBRAS pala Faculdade de Ciências de Wenceslau Braz - FACIBRA. Mestranda em Ciência da Educação pela Facultad Interamericana de Ciências Sociales. E-mail: suelyvsantossvs@gmail.com
} 
metodologias e de acordo com o objeto de pesquisa, para o conhecimento da história, o qual está associado ao cotidiano das pessoas numa concepção de homem, sociedade e cultura. Neste sentido a temática buscará abordar "A importância da cultura local quilombola na prática pedagógica como contribuição a valorização identitária dos discentes na comunidade vila de Juaba, no muncipio de Cametá-Pa no ano de 2019, mostrando-se relevante à medida que o currículo adotado nas escolas dessas povoações segue os mesmos padrões estabelecidos pelo sistema formal de ensino. Dessa forma, além de não considerar a realidade dos alunos e dos demais habitantes, constitui-se de forma imposta, segregando-os a uma educação sem atrativos históricos e regionais, desmembrando o saber e a identidade étinica e cultural da população da Vila de Juaba e do distrito como um todo.

A partir da realidade discente seja a escola e a sociedade se fará a incorporação neste estudo da discussão sobre os conceitos pertinentes que virão abordar a memória e identidade, a cultura e a educação. Dando ênfase a história local conduzindo para uma perspectiva histórica contribuindo dessa forma para uma discussão historiográfica que esteja voltada para o diálogo dos autores dando suporte para este trabalho e partindo então para o estudo da temática para viabilizar a discursão a respeito das variáveis em evidência nesse processo investigativo.

Dessa forma, esse estudo, vem promover no campo pessoal, um maior esclarecimento sobre a cultura local, que está intimamente ligada ao campo pedagógico, pois, os desafios são grandes, há interferências por parte do meio tecnológico, que muitas vezes chega as informações de forma deturpada, trazendo uma consequência negativa, para quem se encanta com o novo, sem se importar com o conhecimento que já possui sobre si mesmo, desencadeando uma recusa com o diferente, que o torna vergonhoso, frente a um mundo globalizado com inúmeras opções de gostos e formas de viver.

Este trabalho, portanto e se deu em forma dissertativa e está organizado em três capítulos que se completam e interligam entre si. Sendo eles:

O capítulo 1, intitulado "A cultura local e o campo educacional”, faz uma abordagem sobre a importancia de se dicutir práticas culturais dentro e for da sala de aula, valorizando saberes ja existente entre os alunos.

A partir desta reflexão, passa-se compreender que a cultura local a identidade do povo circundante o meio escolar tem um significado fundamental para a comunidade da Vila de Juaba, transcendendo além dos elementos religiosos que se interagem a aspectos sociais, econômicos, políticos e culturais..

No capítulo 2, aborda-se a "Prática docente: os desafios na formação do discente", levando a uma abordagem relevante à medida que o currículo adotado nas escolas dessas 
povoações segue os mesmos padrões estabelecidos pelo sistema formal de ensino, segregandoos a uma educação sem atrativos históricos e regionais.

No capítulo 3, com o tema "Educar na diversidade" nos remete a diversidade cultural que sempre existiu e sempre vai existir na sociedade, partindo dessa premissa a escola tem mais espaço e argumento para mostrar aos alunos a importância de respeitar as diferenças, mas não somente para o aluno ser tolerante com outra cultura, ele precisa entender que todos têm os mesmos direitos e que são iguais.

\section{A CULTURA LOCAL E O CAMPO EDUCACIONAL.}

$\mathrm{O}$ aspecto secular da cultura nas áreas coloniais permitiu a mistura de costumes portugueses e africanos, fornecendo exemplos de como a cultura crioula que emergiu em meio aos lugares mais longínquos, como por exemplo, na comunidade da Vila de Juaba. O sincretismo religioso e cultural são marcas deixadas por um povo que vive nas memórias atuais e isso nos remete a um estudo sobre o que vem ser o espaço cultural e de aprendizagem na vida de discentes dessa comunidade. Capaz de despertar no educando o interesse pela cultura através do ensino de história, na perspectiva de valorizar e preservar a história da cultura local. Este é um discurso que engloba a recuperação da memória e das identidades locais que aproxima escola e comunidade.

A relação entre educação e cultura é, portanto, um ponto importante para que exista conhecimentos, saberes, permitindo assim chegar a resultados significativos tanto para discentes, quanto docentes, pois as unidades educacionais, comunidades, são formadas por sujeitos culturais, que cria e recria elementos, reproduz cultura trazida por sujeitos.

Pensando a escola como espaço multicultural, formada por uma diversidade étnica, ARROYO (2004) enfatiza: "não dará para sobreviver nas escolas com pedagogias feitas à medida de imagens superadas, sem relação com o meio cultural"' Tal colocação relaciona-se a ideia de uma pedagogia voltada aos saberes locais.

\subsection{Conceituando cultura}

Dialogar sobre o saber de comunidades remanescentes de quilombo, em especial na comunidade de vila de Juaba, na trajetória de vida a partir de vivências, significa entender que o chamado saberes tradicionais foram criados nas estreitas relações do homem com a natureza. Dessa relação, nascem os saberes necessários para a inserção do homem na sociedade, estabelecendo novas possibilidades de relações sociais, de convívio com o outro, com a 
diferença.

No contexto em que o tema discutido se encaixa, a cultura é entendida como algo em movimento, dinâmico, proporcionando uma relação social, educacional e humana. Como ressalta FREIRE:

O papel ativo do homem em sua e com sua realidade buscando a cultura como acrescentamento ao mundo que ele não fez. A cultura como resultado de seu trabalho. De seu esforço criador e recriador. O homem, afinal, no mundo e com o mundo, como sujeito e não como objeto. [...] descobrir-se-ia criticamente agora, como fazedor desse mundo da cultura. Descobriria que ele, como o letrado, ambos têm um ímpeto de criação e recriação. Descobriria que tanto é cultura um boneco de barro feito pelos artistas, seus irmãos do povo, como também é a obra de um grande escultor, de um grande pintor ou músico. Que cultura é a poesia dos poetas letrados do seu país, como também a poesia do seu cancioneiro popular. Que cultura são as formas de comportarse. Que cultura é toda criação humana (FREIRE, 2006, p. 17).

Os conhecimentos culturais que moradores de um pequeno vilarejo trazem em sua "bagagem" cultural são dentro de seus lócus, muito importantes do ponto de vista da contribuição para a conservação de seus costumes e tradições, uma vez que esses saberes são construídos pela observação. Logo, o conjunto de saberem teóricos e práticos que os moradores possuem oferece uma rica fonte de informações, isso demonstra o quanto é necessário o surgimento e espaço de discussões sobre a importância cultural e saberes tradicionais, buscando caminhos que devem ser compreendidos à luz de uma nova sensibilidade e de uma nova racionalidade a cerca de um povo que busca por um reconhecimento identitário.

Para Loureiro (2001):

\begin{abstract}
A cultura é entendida como uma configuração intelectual, artística e moral de um povo ou, mais amplamente, de uma civilização, e que pode ser compreendida no processo de seu desenvolvimento histórico ou num período delimitado de sua história. É a "soma de todas as criações que melhoram a condição material dos homens ou que expressam a vida intelectual e moral.
\end{abstract}

A cultura é, portanto, uma herança social, que o homem produz ao construir saberes a partir de sua existência. Para o antropólogo inglês, Taylor, conceitua a cultura como um conjunto organizado de vários modos de vida, adquirida pelo indivíduo em uma determinada sociedade. Ao definir dessa forma o termo cultura, Taylor quebra o paradigma de que as pessoas associam cultura a conhecimento, na verdade, se o indivíduo convive nesse espaço cultural, não existe indivíduo sem representações culturais, criando uma identidade própria de uma determinada sociedade.

\title{
1.2 A cultura Local: Um olhar através da escola
}

O ensino de história se propõe a servir-se como instrumento que possibilitará o aluno 
a interagir com o meio no qual está inserido, o conhecimento faz com que o mesmo possa envolver-se e valorizar o seu universo histórico sócio cultural, assim como a trajetória temporal do lugar em que vive. Segundo Santos (2002; p.105). "O método que chama de história do lugar", "como instrumento de recuperação da memória e das identidades locais, bem como de aproximação entre escola e comunidade, gerando nos alunos maior interesse pelo estudo da realidade". Esse é um argumento que vem tratar das identidades locais impostaa aplicação de métodos educativos e de ensino empenhados em formar para a vida em sociedade.

De acordo com BITTENCOURT, (2003, p.165).” O papel do ensino de História na configuração identitária dos alunos é um dos aspectos relevantes para considerar ao proporem-se estudos a história local, muitas vezes esta tem sido objeto de estudo escolar, preservando, no entanto, os mesmos pressupostos norteadores da história nacional. A história local pode simplesmente reproduzir a história do poder local e das classes dominantes, caso se limite a fazer os alunos conhecerem nomes de personagens políticos de outras épocas destacando a vida e obra de antigos prefeitos e demais autoridades. Para evitar tais riscos, é preciso identificar o enfoque e a abordagem de uma história local que crie vínculos com a memória familiar, do trabalho, da migração, das festas.

No que se refere entre o tema e a pesquisa o ensino de história e história local, tem sido de grande relevância porque destacam a importância desse argumento através do diálogo nos conteúdos históricos.

\begin{abstract}
A história local, tem sido indicada como necessária para o ensino por possibilitar a compreensão do entorno do aluno, identificando o passado sempre presente nos vários espaços de convivência - Escola, casa, comunidade, trabalho e lazer, e igualmente por situar os problemas significativos da história do presente. (BITTENCOURT, 2003, p.165).
\end{abstract}

Dentro desta perspectiva este trabalho tem como meta alargar o debate junto à comunidade educativa sobre a necessidade de levar para a sala de aula, ou melhor, de levar para o seu meio de convívio, a importância da valorização da cultura do passado com acultura que é vivida no presente, onde o aluno possa participar da cultura através do ensino nos vários espaços de convivência no qual ele se utiliza da história para se fortalecer, estabelecendo relações com a sociedade. De modo que o ensino de história vem servindo de apoio que fortalece e valoriza o conceito de formação da vida em sociedade, vale ressaltar queo conceito de formação por sua vez está vinculado a consciência das novas gerações no seu lugar de vivência.

Ao viver a experiência os alunos passam gradativamente a observar e a perceber o significado dos imóveis dos momentos e de outras formas materiais construídos no passado, no espaço em que circulam todos os dias. Pode ir, além disso, colaborando para a preservação do patrimônio histórico e da memória local, uma vez que esta passa a ter maior sentido para suas vidas ao se incluírem nela”. (SANTOS, 2002, p.113).

Ao me reportar dentro desses espaços de convivência, onde o próprio aluno pode 
participar de eventos, é saber que ele faz parte deste contexto histórico, mas que deve ser ampliado em um repertório na busca da consciência de significados que esteja ligado a uma necessidade histórica do cotidiano do tempo presente.

\begin{abstract}
A história local geralmente se liga à história do cotidiano ao fazer das pessoas comuns participantes de uma história aparentemente desprovida de importância e estabelecer relações entre os grupos sociais de condições diversas que participaram de entrecruzamentos de histórias, tanto no presente como no passado, a história local, por outro lado, tem sido elaborada por historiadores de diferentes tipos, políticos ou intelectuais de diversas proveniências tem-se dedicado a escrever histórias locais com objetivos distintos, e tais autores geralmente são criadores de memórias mais do que efetivamente de história. A memória é sem dúvida, aspecto relevante na configuração de uma história local tanto para historiadores como para o ensino". (BITTENCOURT, 2003, p. 165).
\end{abstract}

No entanto é importante perceber que a história não é algo vazio que ao viver as experiências do cotidiano os alunos passam a estabelecer relações compartilhando o estudo da história do lugar através do convívio em sociedade.

Acompanhar de perto os espaços que é vivenciado pelos alunos é uma tarefa que se torna importante principalmente quando os alunos começam a participar de conteúdos históricos proporcionados pelo ensino de história, evidenciando realmente que este está vinculado a conteúdos significativos, "vinculam-se a um critério de seleção baseado, direta ou indiretamente, nos problemas do aluno e da sua vida, em sua condição social e cultural". (BITTENCOURT, 2003. p.108).

A ideia de reflexão é trazer para essa discussão a importância dos conteúdos históricos, que parte da necessidade de conhecer melhor a identidade do aluno visto que, a identidade é a base de se reconhecer como sujeitos da história, que impulsionados historicamente pela busca constante do desenvolvimento, possibilita o aluno a se apropriar de conceitos quando este mantém relação com a história local, fato este que é consolidar as habilidades necessárias para desenvolver o pensamento crítico, incluindo nesse caso conteúdos onde o mesmo possa ser trabalhado de acordo com a realidade do aluno, voltado para essa questão os conteúdos históricos dentro de sua abrangência de significados tem colocado em pauta o desenvolvimento dessa temática.

De certa forma as práticas escolares tem um papel fundamental que é compreender, analisando determinados conceitos, como fatos, eventos ou acontecimentos, por sua vez os conceitos passam a fazer parte da vida prática do aluno. A temática que vem sendo discutida neste trabalho busca a melhor forma de compreensão a um questionamento, que visa entender as necessidades dos alunos sabendo que eles devem partilhar de um conhecimento histórico que parte da recuperação da memória por estarem mais perto da escola e da sua comunidade. 
No entanto a temática em questão possibilita contextualizar a integração de um conteúdo que atenda a necessidade do educando, nesse caso a ideia é construir um diálogo juntamente com os alunos, agregando-os aos valores da vida em sociedade. Dessa forma a escola deve organizar um currículo integrando os alunos as discussões sobre o ensino.

\section{PRÁTICA DOCENTE: OS DESAFIOS NA FORMAÇÃO DO DISCENTE.}

Um dos desígnios do processo de formação e aprimoramento de um profissional é a reflexão sobre sua prática. Tal reflexão deve estar ligada a atuações voltadas ao processo de ensino-aprendizagem seus efeitos e inquietudes que causam um ou não contribuições socioculturais econômicas e políticas, nesse sistema de ensino que insiste de forma errônea manter um sistema devassado desvinculado da realidade do mundo contemporâneo.

Segundo esclarece Cortella ao indicar a diferença entre educação e escolarização:

Educação é a formação de uma pessoa; a escolarização é um pedaço dela. A educação é responsabilidade dos pais. A escola é a instituição responsável pela escolarização, e o professor responde por parte dessa escolarização (CORTELLA, 2015).

O educador sendo o responsável por uma parte da escolarização não poderia em sua prática se sobrepor sobre a educação dos alunos, mas na realidade é nítido o inverso dos papeis entre família e escola, cabendo o professor desenvolver em sua prática, atividades que supra a necessidade de uma educação e escolarização. Dessa forma percebe-se a fragilidadeda educação e da escolarização.

Diante de uma prática em que se tem apenas cobranças e não ajuda fica inviável levar o aluno a ter um crescimento significativo, deixando de ter uma valorização familiar, cultural para se dedicar a outras atividades atrativas e enriquecedoras, visto que o que se traz do cotidiano não se torna interessante para o aluno, pois, não é instigado a perguntar, buscar, pesquisar, apenas tem o pronto e acabado. Essa relação com a prática docente está intimamente ligada ao trabalho que se realiza sem parceria com a família.

Essa fragilidade do professor é resultado de sua formação acadêmica e pessoal; ele é fruto dessa sociedade em que estão seus alunos, logo mais uma vítima do sistema educacional.

O sistema nos condiciona à reprodução sem reflexão. Essa forma de pronto e acabado que se recebe dá a ilusão de igualdade, dando uma sensação de que se tem participação no processo, sem perceber que apenas está sendo um sujeito passivo.

Dessa forma, entendemos que um meio principal da formação de professores seja o olhar sobre a prática docente em suas diversas dimensões, e buscar identificar a que seja realmente favorável à essência da sua atividade, não se limitando apenas em procedimentos 
metodológicos que não venha somar à sua prática, mas que abra um leque de opções para de fato atender as necessidades de seu trabalho voltado ao desenvolvimento do ensino aprendizagem. Não se limitando a fórmulas prontas no processo de ensino, pois, ao aplicá-las, está reproduzindo uma metodologia herdada da educação tradicional, e que hoje não se permite essa limitação do professor no processo educativo.

Pois, hoje, a centralidade da educação é a formação integral do aluno, seja cidadania, formação científica, social, entre outras. Ou seja, ajudar os alunos a desenvolverem suas competências intelectuais, em face em todo um conjunto de problemas sociais que estão afetando a juventude, onde o professor deve organizar os conteúdos levando em conta as características individuais, sociais e culturais do contexto em que os alunos vivem.

Pois, hoje não se pode desconhecer que os alunos vêm à escola com uma variedade muito grande de saberes que ele encontra fora da escola, esta, porém, não detém o monopólio do saber.

\subsection{O processo formativo como elemento transformador}

A educação é um instrumento de igualdade social, para tanto, segundo Paulo Freire, a educação tem o papel de libertar o homem, libertá-lo fundamentalmente da sua opressão, consciente de si no meio social, capaz de transformá-lo.

As diferenças sociais e também socioculturais levam a uma discussão de que não tem recebido a mesma atenção e divulgação dos demais aspectos construtivistas, necessitando ser entendido como um processo politicamente construído à partir de visões sociais ajustadas ao desenvolvimento e formação do povo brasileiro, assumindo a responsabilidade de pensar a história dos conceitos de cultura negra e ou afro-brasileira a partir identidades mantenedoras de características históricas, marcadas por lutas e conquistas, proporcionando transformações sociais e políticas, voltadas para uma educação para a vida, uma educação integral, do sujeito do mundo contemporâneo.

Onde, a questão dos diferentes diálogos, da contemporaneidade que se vive é de fundamental importância para que se possa estar construindo esse sujeito crítico, cidadão participativo da sociedade, ou seja, a educação se desloca para uma visão de articulação diversas, são sistemas culturais muito mais do que simplesmente ter um professor que apenas transmite conhecimentos, considerando o aluno como um depósito de informações, portanto, é preciso garantir uma educação de qualidade com acesso pleno a cultura para o desenvolvimento da condição humana, do crescimento individual dos sujeitos, potencializando 
e qualificando as relações sociais, gerando assim, valores e a possibilidade denovas situações que o séculos XXI vem criando acerca da humanidade.

A cultura tem o papel central para transformar o ser humano em um cidadão participante, envolvido, preocupado com seus semelhantes, com a sociedade. A cultura, é, pois, fundamentalmente o processo de assimilação, de informação.

\subsection{Valorização identitária do discente}

A educação se constitui como uma alternativa eficaz, ao promover a inclusão social e valorizar as diferenças e diversidades, baseando-se na formação do indivíduo, a educação se constitui como condição essencial para a superação do preconceito e a solidificação de uma sociedade mais justa e humanizada, pois é na escola que o ser humano tem acesso aos conhecimentos científicos e intervenções sociais na constituição de seu próprio ser.

A escola é um espaço importante na quebra do preconceito e pode contribuir no reconhecimento da identidade, pois sem conhecimento acerca da cultura e identidade o aluno poderá apenas ver o preconceito como uma forma de rejeição da condição humana, desconsiderando o seu próprio eu e as suas diferenças. Esta forma de agir pode levar ao favorecimento de uma vergonha sobre própria identidade, propiciando a um complexo de inferioridade, pois no meio social ainda prevalece a cultura do branqueamento e da desvalorização da cultura afro-brasileira.

\section{EDUCAR NA DIVERSIDADE.}

A educação contemporânea vive um desafio constante, aprimorar a profissão docente nos últimos anos tornou-se muito complexa em função das modificações que vem acontecendo no contexto escolar, seja, modificações sociais, política, econômicas, culturais e pedagógicas. Essas modificações avançam freneticamente em função dos avanços tecnológicos e científicos. Em contrapartida, temos a ação do professor ligada constantemente a uma necessidade de tomada de decisões.

Perrenoud (2002) nos diz, para que o professor seja capaz de tomar de forma hábil essas decisões no contexto escolar, precisa-se estar respaldado em pontos fundamentais, sendo, os saberes, as atividades nos esquemas de ação e a história de vida dos sujeitos. Esses âmbitos pedagógicos estão entrelaçados pelo repertório de conduta do sujeito, ou seja, sua história de vida, suas concepções sociais, a forma como se vê determinado aluno. Buscando entender que a escola é um espaço multicultural e multiideológica, e os alunos são um reflexo da realidade, um reflexo da sociedade. Então quando ele chega à escola, apresenta-se com tantas ideias 
diferentes, formas de agir, pensar, e isso deve ser aproveitado no espaço educacional, porque o papel do professor não é fazer com que o discente não tenha essas posições, mas sim, fazer com que tenham segurança de expor, debater e melhora-las suasideais.

Desde sempre, o professor deve gerar debate, trazer a discussão da diversidade cultural e trazer para a sala de aula de forma a contribuir para o enriquecimento do conhecimento, gerando mais conhecimento ainda. Buscando estudar as origens dos alunos, isso vai dando uma ideia de que a diferença é normal entre todos, que é bom, que é uma qualidade.

Exercer o diálogo e apresentar a diversidade de maneira explícita e natural, buscando formalizar debates e desenvolver estratégias em que diariamente permita expressar a voz do outro, exercitando o respeito mútuo.

Faz-se necessário estar atentos às formas conservadoras retratadas no termo diversidade, tão presente nas falações. Como assegura Nóvoa (2006).

O emprego desse termo acaba por ressoar e legitimar o discurso da deficiência, obscurecendo o significado político das diferenças, nesse discurso a diferença passa a ser definida como diversidade que é entendida quase sempre como a/s variante/s aceitáveis e respeitáveis do projeto hegemônico da normalidade" (NÓVOA, 2006, p. 7).

Ainda sobre tais questionamentos, Silva (2000) afirma:

O debate contemporâneo sobre identidade e diferença não pode ser realizado, no chamado multiculturalismo em educação, simplesmente como uma questão de tolerância e respeito para com a diversidade cultural, por mais edificantes e desejáveis que possam parecer.

Reconhecer a diversidade pode ocultar-se de uma incapacidade de simplesmente aceita sem questionar os mecanismos pelos quais as instituições adotam e passam a separar determinadas identidades culturais, sem observar o meio cultural. Essas formas de "ensinância" bloqueiam a visão que se deveria ter em relação a identidade e a diferença como processo de produção social. Assim, deve-se explicar como a diversidade é ativamente produzida. Fortalecida através uma política curricular e pedagógica.

Espera-se problematizar as alocuções recomendadas pelo governo, na visão de que a escola está acessível a todos e o de que o convívio social com as diferenças induzirá à formação de indivíduos mais complacentes e atentos à diversidade.

A relação professor aluno é um desafio, pelo fato da sala de aula ser um lugar complexo, formada por grupos heterogêneo com inúmeras ideias e saberes, com formações e informações diferenciadas e os agentes da educação, seja professores ou alunos, ao irem para a sala de aula são portadores de um conjunto de valores, de crenças, de esperanças, se apresentam com uma expectativa que estão alheias a dimensão epistemológica, não tendo 
ciência nenhuma capaz de captar de uma maneira sistemática, como por exemplo, o ensino da Matemática de maneira exata. Mas, essa dinâmica que o constitui é capaz de produzir movimento no dia a dia proporcionando uma organização que se aproxime das expectativas geradas em torno do que é uma sala de aula.

O aluno na relação com o professor deve ser estimulado para ativar o interesse do educando e orienta o seu esforço individual para aprender a importância do diálogo. Essa relação não é unilateral e para haver um processo que promova a edificação coletiva do conhecimento é necessária que esta relação seja baseada no diálogo, a autoridade do educador deve existir, mas não tem que agir com autoritarismo, tem sim a ver com a aquisição de confiança e respeito, de disciplina de vida que não se aprende em manuais e sim na própria escola de obstáculos naturais.

\subsection{Reconhecimento de identidade: A escola como espaço cultural.}

É importante saber que o aluno é parte integrante de um processo histórico educativo que ao se integrar na escola ele tem por direito a participação nas disposições das orientações das diferentes atividades e de um ambiente que abarca uma dada complexidade de umproblema. Nesse sentido é comum falar que o trabalho pedagógico realizado é uma tarefa que precisa adequar os alunos a determinados conteúdos para poder chegar às informações no tempo histórico. Segundo os PCNs, (2001, p. 78).

"É importante que o professor crie situações rotineiras, nas suas aulas, de atitudes questionadoras diante dos acontecimentos e das ações dos sujeitos históricos, possibilitando que sejam interpretados e compreendidos a partir das relações (de contradições ou de identidade) que estabelecem com outros sujeitos e outros acontecimentos do seu próprio tempo e de outros tempos e outros lugares. Isto é, relações que estabelecem por suas semelhanças, suas diferenças, suas proximidades, suas dependências, suas continuidades".

Ao tratar de situações rotineiras as aulas de história se tornam dinâmicas se oprofessor realmente estiver preparado para colocar em prática as atividades escolares, no qual se baseia na ideia de que os acontecimentos históricos se tornam significativos para os alunos.Em questão esse é um argumento que deve considerar cotidianamente a participação dos alunos, nas aulas de histórias, partindo sempre de um princípio que leve o aluno a conviver com o ambiente, adequando-os aos seus valores costumes, hábitos e ao econômico, político, social e cultural.

Diante de um determinado tema é preciso compreender e identificar as indagações atuais da história do tempo presente, procurando de certa forma ajudar os alunos a terem entendimento sobre o conteúdo estudado. Afirma ABUD (2003) p.184, "O final da década de 70 e o início dos anos 80 no século passado foram marcadas por mudanças de paradigmas e por 
novas propostas para a construção do conhecimento histórico". Desde esse período então vem se recriando um novo modelo para trabalhar na escola com a disciplina de história dentrode um processo histórico de ensino e aprendizagem. Tendo em vista que os conceitos sempre partem de categorias explicativas, que passam a envolver o cotidiano e a mentalidade do aluno.

\begin{abstract}
A história, como disciplina escolar, também é história". Isto é, também ela como campo de conhecimento, passa por mudanças e transformações que a fazem filha do seu tempo as novas abordagens, os novos objetos, outras fontes, outras linguagens, os novos objetos, outras fontes, outras linguagens foram incorporando ao ensino de história as novas tendências e as correntes historiográfica que entendem a história como construção, aliada a concepções que envolvem o processo de ensino aprendizagem, provocaram transformações bastantes profundas na construção da história como conhecimento escolar. Tais transformações produziram modificações na didática da história e provocaram uma reformulação na prática pedagógica. É necessário que se destaque a introdução e a permanência, nos documentos curriculares, de orientações sobre o uso das novas linguagens, a despeito da inércia da organização escolar no sentido de consolidá-las como práticas cotidianas. (ABUD, 2003, p.184).
\end{abstract}

As abordagens do ensino de história que se insere a temática em discussão, é parte integrante das intervenções pedagógicas de um currículo escolar, que baseado no trabalho de pesquisa histórica este se apresenta dentro de um importante questionamento. Questionamento esse que deve ser considerado principalmente quando se trata da cultura local do aluno. É dever da escola mobilizar-se adequadamente e mostrar para a sociedade que a cultura é algo de grande importância que dentro de um âmbito cultural estar por sua vez passa a construirum conhecimento histórico pautado na vida das pessoas e na organização de uma sociedade.

A escola por ser um lugar privilegiado de aprendizagem e de desenvolvimento do aluno, sendo na construção do conhecimento para o seu desenvolvimento pessoal ou na construção do conhecimento histórico cultural, ela tem o papel de desempenhar no educando diferentes práticas educativas. As práticas educativas é sem dúvida verdadeiros contextos de desenvolvimento pessoal que possibilitam ao aluno modelos de atividade e isso cria no educando uma maneira prática de desenvolver com autonomia seu desenvolvimento, sendo críticos as novas formas ou maneira de aprender.

Contudo, a escola é o lugar onde a intervenção educativa acontece com mais nitidez. Neste sentido entende-se que a escola por ser esse espaço privilegiado, que forma as pessoas através de um conhecimento formal com mais clareza e precisão. Esta por sua vez tem o dever de formar o indivíduo para manter um bom relacionamento dentro e fora da escola. Além disso, a escola deve estar pautada em seu objetivo, mostrando para os educandos que o seu desempenho dentro do próprio espaço escolar acaba influenciando na vida em sociedade da qual ele faz parte.

É dever da escola, trabalhar a cultura local do aluno, buscando sempre reservar esse 
espaço de convivência onde eles possam sentir-se atraente podendo assim vivenciar através do conhecimento diferentes práticas culturais. Considera-se que este é um ponto positivo que traz bons resultados tanto na vida escolar dos alunos, como na vida em sociedade.

Do ponto de vista histórico, o conhecimento pode ser entendido como um procedimento para se chegar a uma verdade sobre um determinado objeto. É essencial que os alunos consigam entender sobre o objeto de conhecimento a ser ensinado e aprendido, pois é a partir da relação do novo com o conhecimento que possui que a aprendizagem ocorre.Portanto, toda experiência adquirida ou construída faz com que a nossa capacidade de conhecer esteja intimamente ligada a nova cultura de aprender. De acordo com (Os Parâmetros Curriculares Nacionais, 2001, p.33). “Considera-se, então, que o ensino de história envolve relações e compromissos com o conhecimento histórico, de caráter científico, com reflexões que se processam no nível pedagógico e com a construção de uma identidade social pelo estudante relacionada às complexidades inerentes à realidade com que convive”.

\section{CONSIDERAÇÕES FINAIS}

O referido trabalho trata sobre a temática A importância da cultura local quilombola na prática pedagógica como contribuição a valorização identitária dosdiscentes na comunidade vila de Juaba, no muncipio de Cametá-PA no ano de 2019 e para a conclusão do trabalho foi feito um trabalho investigativo bibliográfico fundamentando a ação teórica e de campo evidenciado ação pedagógica utilizada na Escola Municipal de Ensino Infantil e Fundamental Professor João Moraes Bitencourt.

Durante a pesquisa buscou-se observar a valorização identitária do discente bem como a prática pedagógica dos professores da referida escola dando ênfase a interrogante central da pesquisa "De que maneira a cultura local esta sendo trabalhada pela pratica PEDAGÓGICA e quais suas contribuiçoes para a valorização identitária do discente nacomunidade da Vila de Juaba, no MUNICÍPIO de Cameta-PA no ano de 2019?"Afirmando que entre as ações observadas no espaço educacional sejam em ordem estrutural, pedagógicae administrativa observa-se as deficiências pelo qual passa o ensino público.

Em relação a valorização identitária do discentes da comunidade de Vila de Juaba, percebe-se a fragilidade e a falta de coerência em relação a cultura e a comunidade na qual está inseria as unidades de ensino, pois, encontram-se dissociadas da realidade do aluno. Embora se tenha mudanças no currículo escolar, que reforçado pela BNCC, mas ainda se tem muito a fazer, uma vez que as escolas não estão preparadas para exercer o papel de elemento transformador social, pois, se vê o aluno como reprodutor de conhecimento e não o ser que produz o 
conhecimento.

A escola é um espaço que atende inúmeras pessoas com diferentes culturas e etnias, portanto, faz-se necessário se trabalhar a história e cultura onde o aluno está inserido e se reconheça enquanto ser identitário.

De certa forma as práticas escolares têm um papel fundamental que é compreender, analisando determinados conceitos, como fatos, eventos ou acontecimentos, por sua vez os conceitos passam a fazer parte da vida prática do aluno. Dialogar sobre o saber de comunidades remanescentes de quilombo, em especial na comunidade de vila de Juaba, na trajetória de vida a partir de vivências, significa entender que o chamado saberes tradicionais foram criados nas estreitas relações do homem com a natureza.

No entanto por meio de determinadas atividades e práticas educativas as culturas através do ensino de história passam ter grandes influências na vida dos indivíduos, estas por sua vez passam a adquirir conhecimentos que na maioria das vezes tem um grande significado na sua vida pessoal. É dever da escola trabalhar a cultura local do aluno, buscando sempre reservar esse espaço de convivência onde eles possam sentir-se atraente podendo assim vivenciar através do conhecimento diferentes práticas culturais

Portanto, trabalhar a valorização e história local no espaço escolar é um direito que muitas vezes acaba sendo negligenciado por falta de fiscalização das políticas públicas, e pela omissão das secretarias de educação que deixam a deseja sobre a formação de sua equipe técnica de apoia a pessoa as 4 scolas do campo, principalmente as escolas quilombolas. Sabe- se que todo processo de mudança exige esforços e perpassa por desconforto, porem se faz urgente e necessário garantir o direito do aluno da educação do campo, para que este tenha sua cidadania assistida em termo de sua formação educacional.

\section{REFERÊNCIA}

ABUD, KÁTIA MARIA. A construção de uma didática da história: algumas ideias sobre a utilização de filmes no ensino. história, São Paulo, p.183-193. 2003.

ARROYO, Miguel G. Experiências de Inovação Educativa: o Currículo na Prática da Escola. In: MOREIRA, Antônio Flávio B. (org.). Currículo: Políticas e Práticas. Campinas, SP: Papirus, 2004.

BARBOSA, Maria C. S.; HORN, Maria da Graça S. Projetos pedagógicos na Educação Infantil. Porto Alegre: Artmed, 2001.

BITTENCOURT, Circe Maria Fernandes, identidade nacional e ensino de história do Brasil. In: KARNAL: Leandro (org.). História na sala de aula: conceitos, práticas e propostas. São 
Paulo: Contexto 2003.

BRASIL. Ministério da Educação. Parâmetros Curriculares Nacionais, $1^{\mathrm{a}}$ a $4^{\mathrm{a}}$ series e $5^{\mathrm{a}}$ a $\mathbf{8}^{\text {a }}$ series. V. 5. História e Geografia. Brasília, 1997.

BRASIL. Ministério da Educação. Parâmetros Curriculares Nacionais: História eGeografia. Ministério da Educação Fundamental. 3. ed. - Brasília: Ministério da Educação. 2001.

CANDAU, V. M. Diferenças culturais, cotidiano escolar e práticas pedagógicas. Currículo sem Fronteiras, v. 11, n. 2, p. 240-255, 2011.

CANDAU, Vera. Multiculturalismo e educação: desafios para a prática pedagógica.

Petrópolis: Vozes, 2003.

CORTELLA, Mário Sergio. Educação, convivência e ética: audácia e esperança.São Paulo: Cortez, 2015.

FREIRE, Paulo. Pedagogia da Autonomia: Saberes necessários à política educativa. Rio de Janeiro: Paz e terra, 1997.

FREIRE, Paulo. Pedagogia da esperança: um reencontro com a Pedagogia do oprimido. São Paulo: Paz e Terra, 2006.

GOMES, Nilma Lino. Indagações sobre currículo: Diversidade e currículo. Educação Básica, 2007.

HAGE, Salomão Mufarrej. Educação do Campo na Amazônia: retratos das escolas multisseriadas no Pará. Belém-PA, gráfica e editora Gutemberg LTDA, 2005.

LARÊDO, Salomão. Terra dos Romualdo, País dos Maparás: Memória da Amazônia Tocantins: Etnoliteratura, Teologia cultural, mito poética, fato memória-auto ficção-mito memória (?). Belém: Salomão Larêdo editora, 2013.

LIBÂNEO, José Carlos. Fundamentos teóricos e práticos do trabalho docente: estudo introdutório sobre pedagogia e didática. 2002. (Tese de doutorado) - Pontifícia Universidade Católica de São Paulo, 2002

LOUREIRO, C. F. B. Educação ambiental e gestão participativa na explicitação e resolução de conflitos. Gestão em Ação, Salvador, v. 7, n. 1, 2001a.

MORIN, Edgar. A cabeça bem feita: repensar a reforma, reformar o pensamento. Rio de Janeiro: Berrand Brasil, 2000.

NÓVOA, A. Histoire et comparaison: essais sur l'education. Lisboa: Educa, 1998. NÓVOA, Antônio (org.). Professores e sua formação. Lisboa, Dom Quixote, 2000.

PERRENOUD, P., \& Thurler, M. G. As Competências para Ensinar no século XXI: a formação dos professores e o desafio da avaliação. Porto Alegre: Artmed Editora. 2002.

PINTO, Benedita Celeste de Moraes. Quilombo do Mola: local de ramificação e ponto de partida para uma reconstrução historiográfica. Recife: ANPHU, 1995 
SANTOS, Joaquim Justino Moura dos. História do lugar: um método de ensino e pesquisa para as escolas de nível médio e fundamental. História, Ciências, Saúde - Manquinhos , v. 9. n. 01, 2002, p. 105-124.

SILVA, Vagner Gonçalves. Observação participante e escrita etnográfica. O In: FONSECA, Maria Nazareth Soares (Org.). Brasil afro-brasileiro-. - 2. Ed. Belo Horizonte 2000. 